\section{Relaunching JIM}

\section{Michael J McPhaul, Editor-in-Chief}

Journal of Investigative Medicine (JIM) begins a new chapter in its publication history.

When JIM first launched 21 years ago, translational research was a term that was not commonly used. Since then, the critical linkage between the conduct of research and the practice of medicine has become increasingly central and the relevance of JIM as a venue to publish such translational research has become especially important.

In this issue, our collection of Experimental Biology Symposia papers captures this critical linkage perfectly. In the first article, Engin summarizes findings linking endoplasmic reticulum stress and the development of type 1 diabetes mellitus. Next, Ehlers describes the use of immune interventions to preserve $\beta$ cell function. Finally, Kulkarni and his colleague describes work in which immune cells have been used to increase $\beta$ cell mass.
Over the past decade, JIM has successfully navigated a variety of challenges, including its conversion to a web-based manuscript submission system, moving from a print-based journal to primarily online and being able to honor funder mandates and offering authors an open access publication option. Despite these successes, the scientific and medical publishing world continues to become increasingly global and competitive. To meet these challenges, the American Federation for Medical Research has chosen to partner with a strong and innovative publisher.

JIM's new publisher, BMJ, represents just such a partner. Its strong global reach and recognized brand will provide ready access to JIM to a broad audience. BMJ has already demonstrated its ready embrace of the opportunities and challenges of the modern publishing environment, and will be well positioned to facilitate the visibility of the journal's high-quality content.
Moving to BMJ is marked by some obvious changes: a new cover design, subtle changes in the article's appearance, the inclusion of features in print and online that are designed to accentuate the important aspects of original research and reaching a global audience through harnessing the breadth of the web and social media. Some features will be enhanced, notably the provision of a 'Fast Track' review for high-impact work. However, one element that will not change is JIM's dedication to excellent and constructive peer review so that our authors may rapidly publish their important research and ultimately affect patient care.

Competing interests MJM is Medical Director, Endocrinology Quest Diagnostics, Nichols Institute San Juan Capistrano, CA, and Editor for Journal of Investigative Medicine High Impact Case Reports.

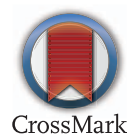

To cite McPhaul MJ. J Investig Med 2016;64:1. Accepted 11 November 2015

J Investig Med 2016;64:1. doi:10.1136/jim-2015-000016 